\title{
SABERES DA DOCÊNCIA APRENDIDOS NO PIBID: UM ESTUDO DE CASO COM PROFESSORES SUPERVISORES DE EDUCAÇÃO FÍSICA
}

\author{
SANTOS, Maria Adriana Borges dos ${ }^{1 *}$; FERREIRA, Heraldo Simões ${ }^{1 * *} ;$ SIMÕES, Luiza Lúlia Feitosa $^{1 * * *}$ \\ ${ }^{1}$ Universidade Estadual do Ceará \\ madriborges@hotmail.com* \\ heraldo.simoes@uece.br** \\ luizalfsimoes@gmail.com ${ }^{* * *}$
}

\section{RESUMO}

Esta investigação buscou compreender e analisar os saberes adquiridos pelos professores supervisores de Educação Física no âmbito do Pibid/Educação Física/UECE para sua formação continuada. Trata-se de uma pesquisa de campo com abordagem qualitativa do tipo estudo de caso realizada na Universidade Estadual do Ceará em 2016. O universo da pesquisa está composto por quatro professores supervisores. Para coletar os dados, realizou-se entrevista semiestruturada. Como resultado, constatou-se que: leituras, pesquisas e experiências se configuram como saberes adquiridos no âmbito do Pibid. Quanto às práticas pedagógicas, os professores destacaram situações de formação, como: reflexão sobre as práticas pedagógicas e criação de materiais alternativos e de conteúdos atualizados pelos licenciandos. Considerou-se, portanto, que o subprojeto Pibid/Educação Física/UECE confirma os pressupostos e possibilita a aquisição de saberes da docência, mas não da mesma maneira e com a mesma profundidade para todos.

PALAVRAS-CHAVE: Formação continuada. Saberes do docente. Educação Física.

\section{KNOWLEDGE OF TEACHING LEARNED IN PIBID: A CASE STUDY WITH TEACHERS PHYSICAL EDUCATION SUPERVISORS}

\section{ABSTRACT}

The overall goal of our research is to understand and analyze the knowledge acquired by supervisors physical education teachers in the Pibid/Physical Education/UECE for their continuing education. We deal with a field research with qualitative approach of a case study conducted at the State University of Ceará in 2016. The research universe were four supervisors teachers. To collect the data we conducted semistructured interviews. As a result we have: reading,
\end{abstract}

research and experiences are by their knowledge acquired in the Pibid. As for pedagogical practices teachers emphasize training situations such as reflection on teaching practices, creation of alternative materials and updated content by licensing. We therefore consider that the subproject Pibid/Physical Education/UECE confirms our assumptions and provides an opportunity to acquire knowledge of teaching, but not the same way and to the same extent for everyone.

KEYWORDS: Continuing education. Knowledge of teaching. Physical Education.

\section{CONOCIMIENTO DE LA ENSEÑANZA APRENDIDO EN PIBID: UN ESTUDIO DE CASO CON PROFESORES SUPERVISORES DE EDUCACIÓN FÍSICA}

\section{RESUMEN}

Esta investigación busca entender y analizar los conocimientos adquiridos por los supervisores profesores de Educación Física en el Pibid/Educación Física/UECE para su educación continua. Se trata de una investigación de campo con enfoque cualitativo del tipo estudio de caso realizado en la Universidad del Estado de Ceará en el año 2016. El universo de la investigación está compuesto por cuatro docentes supervisores. Para recoger los datos, se realizaron entrevistas semiestructuradas. Como resultado se constató que: la lectura, la investigación y las experiencias se configuran por su conocimiento adquirido en el Pibid. Sobre las prácticas pedagógicas, los docentes destacaron situaciones de formación, como: reflexión sobre las prácticas de enseñanza y creación de materiales alternativos y de contenido actualizado de parte de los licenciandos. Se considera que el subproyecto Pibid/Educación Física/UECE confirma las suposiciones y ofrece la oportunidad de adquirir conocimientos de la enseñanza, pero no de la misma manera y en la misma medida para todos.

PALABRAS CLAVE: Educación permanente. Saberes docentes. Educación Física. 


\section{INTRODUÇÃO}

Quando se pensa em educação de qualidade, busca-se refletir sobre a formação dos professores, o que, em virtude da constante transformação dos avanços tecnológicos da sociedade, faz com que seja necessária a formação de educadores capacitados para atuarem em âmbito escolar, que é um dos desafios mais presentes em nosso país. No que diz respeito à formação continuada de professores do Programa Institucional de Bolsa de Iniciação à Docência (Pibid), vem se consolidando como uma das mais importantes iniciativas do país, embora seja um programa destinado à formação inicial.

O subprojeto Pibid do curso de licenciatura em Educação Física da Universidade Estadual do Ceará (UECE) é um marco de grande importância para a instituição, por possibilitar um espaço para as ações de formação dos licenciandos e para o estímulo à docência por intermédio do desenvolvimento de suas ações, como uma nova proposta de incentivo e valorização do magistério.

O objetivo geral de nossa investigação foi compreender e analisar os saberes adquiridos pelos professores supervisores de Educação Física no âmbito do Pibid/Educação Física/UECE para sua formação continuada. Também contamos com os seguintes objetivos específicos: identificar mudanças no trato pedagógico dos professores supervisores do Pibid/Educação Física/UECE no processo de formação continuada e verificar se o Pibid/Educação Física/UECE favorece experiências incentivadoras para a formação continuada dos professores supervisores do Pibid/Educação Física/UECE.

No tópico a seguir, podemos discorrer com mais propriedade sobre os saberes inerentes à formação de professores no campo da educação e no contexto da escola.

\section{OS SABERES DOCENTES E SUA RELAÇÃO COM A FORMAÇÃO PROFISSIONAL DOS PROFESSORES E COM O EXERCÍCIO DA DOCÊNCIA}

Nas palavras de Larrosa (2015), podemos constatar que o saber da experiência se dá na relação entre o conhecimento e a vida humana. Mas não o conhecimento como mercadoria, mas não a vida vista apenas do ponto de vista biológico. Este é o saber da 
experiência: o que se adquire no modo como alguém vai responder ao que lhe está acontecendo ao longo da vida e no modo como vamos dando sentido ao acontecer do que nos acontece.

Se a experiência é o que nos acontece e se o saber da experiência tem a ver com a elaboração do sentido ou do sem sentido do que nos acontece, trata-se de um saber finito, ligado à experiência de um indivíduo ou de uma comunidade humana particular. O saber da experiência é um saber particular, subjetivo, relativo, contingente, pessoal. Se a experiência não é o que acontece, mas o que nos acontece, duas pessoas, ainda que enfrentem o mesmo acontecimento, não fazem a mesma experiência (LARROSA, 2015).

Ao nos questionarmos sobre o que significa ser uma pessoa sabida, deparamo-nos com outros questionamentos que dizem respeito ao dia a dia da vida do professor, às relações com pares e com alunos, às suas buscas por conhecimentos. O saber tem a ver com a capacidade de aprender a realidade e se constitui de forma individual e coletiva.

O saber não é algo fixo e acabado, pelo contrário, ele é gradativo e dinâmico, o professor agrega saberes das experiências constantemente no dia a dia (TARDIF, 2014). O saber se constitui nas leituras, nas experiências e gestão em sala de aula, nos planejamentos dos professores e nas buscas pedagógicas e científicas dos professores (LARROSA, 2015).

Recorremos aos escritos de Tardif (2014) para embasarmos esses saberes, uma vez que esse autor é um estudioso na área e discorre com propriedade sobre tal assunto. Ao se questionar sobre os saberes que servem de base ao ofício de professor, fica claro para Tardif (2014) que a questão do saber dos docentes não pode ser separada das outras dimensões do ensino, do trabalho e da profissão. É um saber que está relacionado com a pessoa, com a identidade do professor, com sua experiência de vida e com sua experiência profissional, levando em consideração as relações do educador com os alunos em sala de aula e com os outros atores da escola.

Estamos em consonância com Larrosa (2015) ao assinalar que o saber da experiência não se trata da verdade do que são as coisas, mas do sentido ou do sem sentido do que nos acontece. Esse saber tem algumas características essenciais que se opõem ponto por ponto ao que entendemos como conhecimento. 
Quando nos referimos a Garcia (1999), ele aponta o saber como o elemento legitimador da profissão que é justificado no trabalho com o compromisso de transformar esse conhecimento em aprendizagem relevante para o aluno. Para tanto, Garcia (1999) afirma que o conhecimento e o aluno têm se transformado em uma velocidade muito grande, daí a necessidade de o professor continuar a aprender.

A partir do exposto, recorremos aos estudos de Tardif (2014) para discorrermos sobre esse saber que acompanha o docente em seu dia a dia em âmbito escolar. Tardif (2014) utiliza-se de dois termos para explicar os saberes do professor: mentalismo e sociologismo; para tal, existe a articulação entre aspectos sociais e individuais. Tardif $(2014$, p. 13) nos afirma que "[...] nos ofícios e profissões não existe conhecimento sem reconhecimento social". Sempre aprendemos com os outros, seja em ambiente de trabalho, seja em ambiente familiar, seja em qualquer outro ambiente, somos influenciados pelos saberes coletivos.

Para Tardif (2014), saber é social e apresenta para isso alguns motivos: em primeiro lugar, é social porque é partilhado por um grupo de agentes, os professores, que possuem uma formação comum, trabalham em uma mesma organização e estão sujeitos, por causa da estrutura coletiva de seu trabalho cotidiano, a condicionamentos e recursos compatíveis, entre os quais programas, materiais a serem ensinados, regras do estabelecimento; em segundo lugar, o professor nunca define sozinho em si mesmo o seu próprio saber profissional. Nesse sentido, Tardif $(2014$, p. 13) frisa “[...] que o professor saber ensinar não constitui um problema cognitivo ou epistemológico, mas sim uma questão social”. Em terceiro lugar, esse saber também é social, por ser a própria prática social o objeto desse saber; em quarto lugar, o que os professores ensinam e sua maneira de ensinar evoluem com o tempo e com as mudanças sociais; em quinto e último lugar, o saber do professor se constrói ao longo de uma carreira profissional na qual o docente aprende a dominar seu ambiente de trabalho (TARDIF, 2014).

O saber do professor é, além de representações mentais, um saber ligado a uma situação de trabalho com os outros: alunos, colegas, pais. Esses saberes são classificados em quatro tipos diferentes implicados na atividade docente, como mostra o quadro 1 , adiante (TARDIF, 2014). 
Quadro 1 - Classificação dos saberes implicados na atividade docente

\begin{tabular}{|l|l|}
\hline \multicolumn{1}{|c|}{ SABER } & \multicolumn{1}{c|}{ DEFINIÇÃO } \\
\hline Saberes da formação profissional & $\begin{array}{l}\text { São os saberes transmitidos pelas instituições de formação de professores } \\
\text { (escolas normais ou faculdades de ciências da educação) e os saberes das } \\
\text { práticas pedagógicas. }\end{array}$ \\
\hline Saberes disciplinares & $\begin{array}{l}\text { São os saberes que competem às disciplinas, como: Matemática, História, } \\
\text { Educação Física, etc., que são transmitidos nos cursos e departamentos } \\
\text { universitários. }\end{array}$ \\
\hline Saberes curriculares & $\begin{array}{l}\text { São os saberes correspondentes aos discursos, objetivos, conteúdos e métodos a } \\
\text { partir dos quais a instituição escolar categoriza e apresenta os saberes sociais por } \\
\text { ela definidos e selecionados como modelos da cultura erudita. }\end{array}$ \\
\hline Saberes experienciais & $\begin{array}{l}\text { São os saberes constitutivos da prática docente, os quais se incorporam às } \\
\text { experiências individuais e coletivas sob a forma de hábitos e habilidades de } \\
\text { saber fazer e de saber ser. }\end{array}$ \\
\hline
\end{tabular}

Fonte: Tardif (2014).

Dando prosseguimento sobre os saberes, Garcia (1999) aponta as seguintes categorias de experiências acerca do aprender a ensinar que influem nas crenças e conhecimentos que os professores têm sobre o ensino:

- Experiência pessoal: inclui aspectos da vida que conformam determinada visão do mundo, crenças em relação a si próprio e aos outros, ideias sobre a relação entre escola e sociedade, bem como família e cultura. A origem socioeconômica, étnica, religiosa e de gênero pode afetar as crenças sobre como se aprende a ensinar;

- Experiência baseada em conhecimento formal: inclui o conhecimento formal, entendido como aquele que é trabalhado na escola, as crenças sobre as matérias que se ensinam e como se devem ensinar;

- Experiência escolar e de sala de aula: inclui todas as experiências vividas como estudante que contribuem para formar uma ideia sobre o que é ensinar e qual é o trabalho do professor.

A relação constitutiva entre experiência e formação é que a experiência é algo que forma (LARROSA, 2015), e é mediante o exercício docente e a reflexividade crítica sobre as práticas que o professor se forma (RABELO; SILVA, 2013). Consideramos, pois, que o professor, sujeito da experiência, é um ser munido de reflexividade crítica.

Gauthier et al. (2006) demonstram que a experiência de um saber efetivamente específico à classe profissional dos professores é o saber da ação pedagógica. Os autores, ao 
discorrerem sobre um ofício sem saberes, citam que, nas condições essenciais para ensinar, não basta conhecer o conteúdo, não basta ter talento, não basta ter bom senso, não basta seguir sua intuição, não basta ter cultura e, por fim, não basta ter experiência, é necessário que o professor contemple um conjunto de saberes no exercício do magistério, e não um saber pedagógico específico (GAUTHIER et al., 2006).

Para Gauthier et al. (2006), o saber experiencial ocupa um lugar muito importante no ensino e precisa ser alimentado, orientado por um saber anterior mais formal, que pode ser de apoio para interpretar os acontecimentos presentes e criar soluções novas.

No contexto sobre saberes sem ofício, Gauthier et al. (2006) fazem críticas às pesquisas behavioristas e piagetianas ao afirmarem que há nesses estudos o esvaziamento do contexto concreto de exercício do ensino. As experiências behavioristas foram desenvolvidas sem levar em conta o professor real, sozinho na sala de aula a distribuir reforços a um determinado grupo de alunos. Outras, inspiradas na psicologia humanista, não se preocuparam o bastante com as consequências concretas para o professor de partir das necessidades e interesses do aluno. Confundiu-se, desse modo, o contexto coletivo do ensino com o contexto individual da relação terapêutica. Outras, ainda seguindo a tradição piagetiana, imaginaram o ensino como se ele se desenvolvesse numa relação clínica com um único sujeito.

Para esses saberes sem ofício, Gauthier et al. (2006) afirmam que são ideias preconcebidas que prejudicam o processo de profissionalização do ensino, ao negar a complexidade do ensino e impedir o surgimento de um saber profissional. Os referidos autores ainda nos esclarecem que, embora o professor viva muitas experiências das quais tira grande proveito, tais experiências, infelizmente, permanecem confinadas ao segredo da sala de aula.

Os saberes classificados por Gauthier e seus colaboradores (2006) são seis, como mostra o quadro 2, a seguir. 
Quadro 2-O reservatório de saberes

\begin{tabular}{|c|c|c|c|c|c|}
\hline $\begin{array}{c}\text { Saberes } \\
\text { disciplinares }\end{array}$ & $\begin{array}{c}\text { Saberes } \\
\text { curriculares }\end{array}$ & $\begin{array}{l}\text { Saberes das } \\
\text { ciências da } \\
\text { educação }\end{array}$ & $\begin{array}{l}\text { Saberes da } \\
\text { tradição } \\
\text { pedagógica }\end{array}$ & $\begin{array}{c}\text { Saberes } \\
\text { experienciais }\end{array}$ & $\begin{array}{c}\text { Saberes da ação } \\
\text { pedagógica }\end{array}$ \\
\hline A matéria. & O programa. & & O uso. & & $\begin{array}{l}\text { O repertório de } \\
\text { conhecimentos } \\
\text { do ensino ou a } \\
\text { jurisprudência } \\
\text { pública validada. }\end{array}$ \\
\hline $\begin{array}{l}\text { Aprendidos nas } \\
\text { disciplinas da } \\
\text { faculdade. }\end{array}$ & $\begin{array}{l}\text { Selecionados e } \\
\text { produzidos } \\
\text { pelas ciências e } \\
\text { transformados } \\
\text { nos programas } \\
\text { escolares. }\end{array}$ & $\begin{array}{c}\text { Adquirido } \\
\text { durante a } \\
\text { formação em seu } \\
\text { trabalho, tais } \\
\text { como: conhecer } \\
\text { como funciona a } \\
\text { gestão da escola, } \\
\text { violência entre os } \\
\text { jovens, } \\
\text { diversidade } \\
\text { cultural, um } \\
\text { conjunto de } \\
\text { saberes que é } \\
\text { comum ao } \\
\text { professor. }\end{array}$ & $\begin{array}{c}\text { É o saber dar } \\
\text { aula. }\end{array}$ & $\begin{array}{c}\text { Aprender através } \\
\text { de suas próprias } \\
\text { experiências } \\
\text { significa viver um } \\
\text { momento } \\
\text { particular, em } \\
\text { que se limita ao } \\
\text { experiencial pelo } \\
\text { fato de ser feito } \\
\text { de pressupostos } \\
\text { e de argumentos } \\
\text { que não são } \\
\text { verificados por } \\
\text { meio de métodos } \\
\text { científicos. }\end{array}$ & $\begin{array}{c}\text { É o saber } \\
\text { experiencial dos } \\
\text { professores a } \\
\text { partir do } \\
\text { momento em } \\
\text { que se torna } \\
\text { público e que é } \\
\text { testado através } \\
\text { das pesquisas em } \\
\text { sala de aula. } \\
\text { Quando os } \\
\text { julgamentos dos } \\
\text { professores e os } \\
\text { motivos que lhes } \\
\text { servem de apoio } \\
\text { podem ser } \\
\text { comparados. }\end{array}$ \\
\hline
\end{tabular}

Fonte: Gauthier et al. (2006, p. 29).

\section{SUBPROJETO PIBID/EDUCAÇÃO FÍSICA/UECE: REFLEXÕES}

Embora o Programa Institucional de Bolsa de Iniciação à Docência (Pibid) da Universidade Estadual do Ceará (UECE) tenha sido implantado em 2009, somente em 2012 é inserido no curso de licenciatura em Educação Física com o primeiro subprojeto. Dando prosseguimento à proposta institucional, em 2013 é lançado o segundo subprojeto em Educação Física, com vigência de quatro anos, iniciando as atividades em março de 2014 até março de 2016, primeiro ciclo, e dando início ao segundo ciclo nessa mesma data.

Os subprojetos Pibid/Educação Física/UECE apresentam propostas de formação que visam estabelecer diálogos entre a universidade e as escolas públicas, professores e alunos, promovendo, assim, uma maior aproximação entre os acadêmicos de licenciatura e a área de Educação Física Escolar. Esses subprojetos encontram-se em consonância com a proposta institucional do Pibid/UECE, o primeiro, de 2012, intitulado Ampliação da perspectiva de formação em Educação Física: aprendendo a ensinar; e o segundo, de 2013, intitulado Educação 
Física na escola e saúde: uma proposta para formação de futuros professores. Ambos os subprojetos têm sua pertinência frisada em:

\begin{abstract}
Valorizar a formação dos futuros professores da área com base no conhecimento da escola, de abrir espaços para a inovação no modo de ensinar a docência e de assegurar mais qualidade à formação profissional no âmbito da licenciatura em Educação Física. [...] No fato de o contato direto com a realidade poder abrir espaço para uma melhor compreensão da relação teoria e prática no ensino da Educação Física na escola, propiciando ao acadêmico (futuro professor) ativar seus recursos intelectuais (conceitos, teorias, crenças, técnicas), diagnosticar a situação, elaborar estratégias de intervenção e prever o curso a-posteriori dos acontecimentos, contribuindo para uma formação baseada na prática da reflexão sobre a prática e para a construção de uma cultura corporal mais reflexiva e autônoma por parte desses futuros profissionais [...]. (UECE, 2012, p. 2).
\end{abstract}

[...] tem como caráter principal a formação de futuros docentes, tentando aliar os conhecimentos teóricos e científicos adquiridos durante a licenciatura com a práxis pedagógica necessária na atuação escolar. [...] Pretende-se inserir o aluno da licenciatura no contexto escolar, por meio de ações práticas e teóricas, não se detendo apenas às dimensões procedimentais, mas sobretudo fazendo-o compreender as dimensões cognitivas e afetivas necessárias ao exercício da docência. Propõe-se neste projeto uma participação efetiva e ativa do educando na escola, compreendendo suas nuances, estruturas materiais e física, proporcionando tomadas de decisões e resoluções de problemas advindos da docência [...]. (UECE, 2013, p. 2).

A proposta de 2012 é embasada na questão histórica da Educação Física Escolar, desde sua introdução na escola em 1951, num contexto tecnicista e excludente da saúde, aos dias atuais, em que a disciplina é legalmente tida como "componente curricular obrigatório da Educação Básica". Essa Educação Física, como componente curricular da Educação Básica, dispõe de três blocos de conteúdos dispostos em conformidade com três dimensões, que são: conceitual, atitudinal e procedimental. Já a proposta de 2013 é justificada principalmente sobre parâmetros da questão da saúde, com preocupação com questões como obesidade e outras doenças relacionadas à qualidade de vida dos alunos, levando em conta os aspectos conceituais, procedimentais e atitudinais em consonância com os blocos de conteúdos da Educação Física Escolar sugeridos pelos Parâmetros Curriculares Nacionais (PCNs) (BRASIL, 1996).

A partir das propostas, são definidas ações com o propósito de organizar os processos pedagógicos no ambiente escolar, promovendo uma Educação Física bem planejada e realizada em conformidade com a teoria. Dessa forma, temos as seguintes ações, no quadro 3, definidas pelos Subprojetos de Educação Física/Pibid/UECE. 
Quadro 3 - Ações dos subprojetos Educação Física/UECE

\begin{tabular}{|c|c|}
\hline \multicolumn{2}{|c|}{ Planos de ações dos subprojetos Pibid/UECE da área da Educação Física } \\
\hline Subprojeto Educação Física/UECE - 2012 & Subprojeto Educação Física/UECE - 2012 \\
\hline $\begin{array}{l}\text { a) Familiarização do grupo consigo e com a escola; } \\
\text { b) Realização de um diagnóstico da escola e aulas } \\
\text { de Educação Física escolar; } \\
\text { c) Ensinar Educação Física na escola; } \\
\text { d) Movimentar a escola: outras possibilidades; } \\
\text { e) Socialização da experiência e dos resultados do } \\
\text { subprojeto. }\end{array}$ & $\begin{array}{l}\text { a) Realizar ciclo de seminários integradores com a escola } \\
\text { e a universidade; } \\
\text { b) Desenvolver estudos sobre educação e saúde; } \\
\text { c) Realizar diagnóstico dos espaços recreativos e desportivos } \\
\text { existentes nas escolas parceiras; } \\
\text { d) Realizar avaliações físicas dos estudantes das escolas } \\
\text { parceiras; } \\
\text { e) Realizar ações que promovam hábitos alimentares } \\
\text { saudáveis e práticas de atividade física; } \\
\text { f) Produzir um memorial da experiência formativa vivenciada; } \\
\text { g) Realizar fóruns de socialização das experiências do } \\
\text { subprojeto na escola; } \\
\text { h) Participar de eventos científicos com apresentação de } \\
\text { trabalhos; } \\
\text { i) Elaborar relatórios das atividades desenvolvidas sempre } \\
\text { que solicitado pela Coordenação Institucional do Pibid. }\end{array}$ \\
\hline
\end{tabular}

Fonte: Elaboração própria a partir do detalhamento das ações dos subprojetos Pibid/UECE/Educação Física (2016).

Embora essas ações apresentem variações em seus planos de detalhamentos, ambas evidenciam questões de perspectivas semelhantes. Dessa maneira, apresentamos, de forma simplificada, com base nos Subprojetos Educação Física/UECE (2012, 2013), como são desenvolvidos os planos de ações para ambos os subprojetos: a princípio, é desenvolvido um plano de socialização integrando escola-universidade e professores-alunos-grupo gestor da escola, em que são envolvidas sessões de estudos fortalecendo o repertório dos saberes dos profissionais e licenciandos; em outros momentos de planejamentos, são elaborados roteiros para realizar diagnósticos tanto dos espaços físicos como das funções pedagógicas dos professores.

Continuando a discorrer sobre a análise dos detalhamentos das ações, os momentos de planejamentos são bem frequentes entre os professores e licenciandos para as ações previstas, favorecendo o desenvolvimento de momentos de reflexão sobre a prática docente nas aulas de Educação Física na escola, tendo como base os conteúdos dos blocos de conhecimentos propostos pelos PCNs (BRASIL, 1996).

As ações são postas ao coletivo mediante construção de painel de notícia, organização de campeonatos esportivos, sábados recreativos, festivais de dança e de teatro e seminários de apresentação. As vivências são registradas por meio de elaboração de memoriais pelos licenciandos e por fórum de socialização de experiências e resultados dos subprojetos. 


\section{FORMAÇÃO DE PROFESSORES}

A formação de professores é a área de conhecimentos, de investigações e de propostas teóricas que, no âmbito da Didática e da Organização Escolar, estuda os processos através dos quais os professores, em formação ou em exercício, implicam-se, individualmente ou em equipe, em experiências de aprendizagem através das quais adquirem ou melhoram os seus conhecimentos, competências e disposições, o que lhes permite intervir profissionalmente no desenvolvimento do seu ensino, do currículo e da escola, com o objetivo de melhorar a qualidade da educação que os alunos recebem (GARCIA, 1999).

Rabelo e Silva (2013) nos assinalam que a boa formação não se edifica por acúmulo de cursos, de conhecimentos ou de técnicas, mas mediante um trabalho de reflexividade crítica sobre as práticas e de construção e reconstrução permanente de uma identidade pessoal, constituindo, assim, uma formação continuada com qualidade. É durante o exercício da docência que o professor realiza ações e reflexões para constituir sua formação continuada. Quando pensamos na formação do professor de Educação Física, remetemo-nos aos séculos XIX e XX, quando a Educação Física era estreitamente ligada a aspectos higienistas, militaristas e esportistas. A Educação Física tinha caráter de formação, eminentemente, técnico-prático.

No processo de formação do professor, Lazzarotti Filho, Silva e Pires (2013) destacam e diferenciam três saberes no campo da Educação Física: o Saber das Práticas Corporais (SDPC); o Saber sobre as Práticas Corporais (SSPC); e o Saber Pedagógico das Práticas Corporais (SPDPC).

O SDPC diz respeito a saberes técnicos, táticos e estéticos expressos pelo saber fazer nos quais o ser humano manifesta integralmente sua corporalidade, eixo importante constituinte da especificidade da Educação Física, o qual também se manifesta na formação de professores como forma de autorreprodução e desenvolvimento.

O SSPC é entendido como aquele conhecimento desenvolvido, sistematizado e validado cientificamente sobre uma determinada prática corporal. Esse saber foi trazido para a Educação Física de outros campos científicos, em parte, com suas nomenclaturas de origem, tal como "fisiologia do exercício" ou "história da ginástica", constituindo-se como um discurso sobre, conforme denomina Betti (2007), e como o conhecimento sobre o conteúdo, de acordo com Nascimento (2007). 
Já o SPDPC identifica o saber pedagógico desenvolvido a partir das e sobre as práticas corporais, isto é, o saber ensinar oriundo da capacidade de transformação, dos conhecimentos historicamente produzidos e socialmente reconhecidos como necessários e válidos em conhecimentos didático-pedagógicos (LAZZAROTTI FILHO; SILVA; PIRES, 2013).

Ainda conforme Lazzarotti Filho, Silva e Pires (2013), a formação em Educação Física, de maneira geral, ao longo dos anos, vem se modificando, mas a especificidade do SDPC sempre compôs os currículos, expressando-se em denominações de disciplinas da cultura esportiva como disciplinas teórico-práticas, como conhecimentos identificadores da área ou como disciplinas práticas. Esses saberes ainda marcam os currículos dos cursos de Educação Física; em boa parte deles, sua perspectiva técnica e reprodutora do modelo esportivo tem sido fortemente criticada por autores como Bracht (1992) e Daolio (1998). Dessa maneira, a Educação Física passa a ter novo campo epistemológico, frisado não só na prática e técnica dos ensinamentos, mas nos conteúdos e nas ações didático-pedagógicas.

O Parecer n 9, de 8 de maio de 2001, do Conselho Nacional de Educação, considera que, na formação de professores no território brasileiro, há a predominância do método tradicional, havendo a necessidade de revisão do processo de formação de professores com os seguintes destaques: o desenvolvimento de competências necessárias para atuar num novo cenário, a inexistência de uma proposta integrada de formação para professores de Educação Básica, a indicação de ausência no processo de estágio de espaço institucional que permita a integração no espaço e no tempo do planejamento conjunto entre profissionais dos cursos de formação e os da escola de Educação Básica, a superação da ideia de que o estágio é o espaço reservado à prática, enquanto em sala de aula trabalham-se a teoria e a superação da fragmentação do conhecimento no processo de formação de professores, situando os saberes disciplinares nos conjuntos do conhecimento escolar.

\section{METOdOLOGIA}

Este estudo consiste em uma pesquisa de campo com abordagem qualitativa do tipo estudo de caso. Para Bogdan e Biklen (1994, p. 16), “[...] a abordagem qualitativa privilegia, essencialmente, a compreensão dos comportamentos a partir da perspectiva dos sujeitos da 
investigação". A pesquisa foi realizada na Universidade Estadual do Ceará em 2016. O universo da pesquisa foi composto por quatro professores supervisores (PS) do Pibid/Educação Física/UECE, sendo dois atuantes e dois egressos. Os professores tinham entre 28 e 49 anos, com no mínimo dois anos de atuação no Pibid como PS e entre quatro e 31 anos de experiência no magistério. Os PS são docentes de escolas públicas de Educação Básica, supervisionando no mínimo cinco e no máximo dez bolsistas da licenciatura.

A coleta dos dados se deu por meio de uma entrevista semiestruturada com duas perguntas norteadoras. Vale reforçar que os participantes tiveram sua identidade preservada e que não sofreram nenhum risco ou dano físico, mental ou social.

\title{
6 RESULTADOS E DISCUSSÕES
}

Como foi apresentado no percurso metodológico, analisamos os dados a partir de duas temáticas: os saberes adquiridos pelos professores supervisores de Educação Física no âmbito do Pibid e a formação continuada. Os parágrafos a seguir entrelaçam a subjetividade dos sujeitos em suas relações com o contexto cultural do qual fazem parte e os achados na literatura.

A respeito do questionamento: "Que práticas e saberes mobilizados no âmbito do Pibid contribuem para sua formação continuada?", podemos observar as seguintes falas dos PS:

\begin{abstract}
Logo no começo, foram disponibilizados artigos sobre professor, professor pesquisador, cotidiano da escola, artigos específicos da própria área que eu nunca tinha lido, nunca tive o contato, então isso foi compartilhado dentro do grupo; a gente fazia as leituras e depois dialogava, refletia e tentava pegar os pontos principais para levar para a melhoria da prática. As publicações que eu aprendi a olhar para a minha aula, para as minhas experiências nas aulas da Educação Física; eu aprendi a ver, a observar, a escrever aquilo, a refletir e a produzir um texto acadêmico que fosse trazer contribuições também para mim, que eu ia fazer esse processo de observação e depois eu ia sistematizar e também disponibilizar boas experiências. Então, o Pibid me trouxe essas experiências benéficas, por ter aprendido, tanto que, após o Pibid, eu consegui pegar experiências feitas por mim na aula e já fui publicar artigos sozinha. Uma coisa que eu gostava muito no Pibid eram os eventos de que a gente participava, tinha as mesas que traziam professores para estarem dialogando sobre assuntos da escola, então eram palestras ótimas, maravilhosas, que ampliavam ainda mais a nossa visão da educação enquanto professor, enquanto professor de Educação Física; era muito bom. (PS1).
\end{abstract}

Eu acho a prática melhor. Aqui, aos sábados, a gente abre essa escola para a comunidade e para os alunos [...]; todas as ações que a gente citava, todos sempre abraçaram, então ter uma equipe boa já tem meio caminho andado para conseguir implementar as ações que eu queria [...]. Os estagiários traziam materiais da UECE, 
arrumaram um slackline, trouxeram para a escola para criarem uma oficina de modalidades alternativas, produziam material, por exemplo: golfe, beisebol e outras atividades que fogem do quarteto fantástico, que é futebol, vôlei, basquete e handebol. Apesar de não ter tantos materiais e espaços adequados, já é um ganho para esse aluno [do Ensino Médio] também. [...] O que eu gostaria de destacar eram essas práticas. Teve outras ações, mais essas eu acho que foram as mais importantes e as mais significativas na minha formação. [...] Os saberes que contribuíram para minha formação continuada são esses saberes novos, por exemplo, eu não tive essa disciplina de Modalidades Alternativas, então isso trouxe conhecimento, e eu passei a usar até nas escolas fundamentais, porque eu também sou professor temporário em Caucaia; o próprio slackline eu pedi para ficar por uma semana para levar para meus alunos de Caucaia. Então, essas modalidades alternativas fazem com que você mesmo produza seu material para dar aulas. Então, para eles, foi maravilhoso, trouxe essa vivência para mim, e isso também fez com que eu disseminasse nas outras escolas em que eu trabalho essas modalidades alternativas; essas atividades extras fazem a gente sair do paradigma da bola. (PS2).

Primeiro foram os conteúdos que os licenciados trouxeram quando foram dar uma aula na escola. [...] Eu estou sempre comprando livros, e os alunos sempre traziam livros atualizados da universidade, o que eles achavam de novo na universidade eles traziam e diziam que eram livros mais atualizados. Tinha sempre esse 'feedback' entre a gente, então foi maravilhoso, praticamente eu não parava de estudar. Você tem que estar o tempo todo estudando, pesquisando, é maravilhoso. (PS3).

Nessa interação do aluno com o professor e do professor com os bolsistas, a gente, sempre que possível, tenta estreitar essa relação com as atividades práticas. Os bolsistas, vez por outra, fazem jogos competitivos com os alunos, ou então a gente promove torneio entre os próprios alunos. Eu deixo a cargo dos bolsistas também algumas situações para que eles tirem as dúvidas dos alunos das aulas que são ministradas em sala de aula, para que eles aos poucos consigam entrar nesse contexto de ter que enfrentar uma turma, enfrentar no sentido de estarem à frente do comando da aula, de ministrarem a aula. [...] Essas práticas vivenciadas contribuíram para minha formação, claro! Com certeza, contribuíram, sim, porque a gente passou por situações novas, até de relembrar o começo, de quando eu era ainda igual a eles, apenas estudante de Educação Física; houve esse crescimento profissional. (PS4).

Nos discursos de PS1, PS2 e PS3, identificamos que as leituras, as experiências e as relações construídas se configuram como saberes adquiridos. Sendo que PS1 coloca, de maneira bem mais evidente, os saberes advindos dos artigos, publicações, eventos e palestras; PS4 não destaca nem faz referência a saberes e práticas que possam ser evidenciados como contribuintes para sua formação continuada. Embora não expresse tal situação, PS4 destaca que sua experiência contribuiu para sua melhoria como professor em sala de aula.

Entendemos, pois, que essa melhoria na pessoa do professor se configura como desenvolvimento profissional, entendido, neste caso, como formação continuada deste PS, uma vez que sua identidade de docente passa por alterações e melhorias. 
Quanto às práticas pedagógicas, PS1, PS2 e PS3 elencam e destacam situações de formação. PS1 aponta a dialogicidade e a reflexão; PS2 destaca as oficinas de criação de materiais alternativos; e PS3 frisa os conteúdos atualizados trazidos pelos licenciandos para as aulas.

Conforme Tardif (2014), tornar-se professor é um processo longo e complexo, que engloba os saberes e as vivências da formação inicial, da formação continuada e das diversas experiências. Esse conjunto de saberes e experiências vai se concretizando, criando formas que se traduzem no âmbito das práticas pedagógicas dos professores. Dessa maneira, cada docente se forma de acordo com suas experiências pessoais e profissionais.

O Parecer no 9 (BRASIL, 2001) apresenta, de um modo geral, um panorama de predominância na formação de professores no território nacional, afirmando ser essa predominância o método tradicional. Conforme Lazzarotti Filho, Silva e Pires (2013), na Educação Física, durante muitos anos, prevaleceu o saber tradicional, e a especificidade da técnica compôs os currículos, expressando-se em denominações de disciplinas da cultura esportiva como conhecimentos identificadores da área ou como disciplinas práticas.

Dessa maneira, os saberes e as experiências adquiridos no âmbito do Pibid por esses professores supervisores são mudanças que favorecem não só a formação continuada deles como também o campo epistemológico da Educação Física.

Dando prosseguimento às indagações, perguntamos aos PS: “Como você analisa a sua prática pedagógica no contexto de trabalho escolar antes e depois de participar do Pibid? Detalhe com exemplos.", obtendo como respostas:

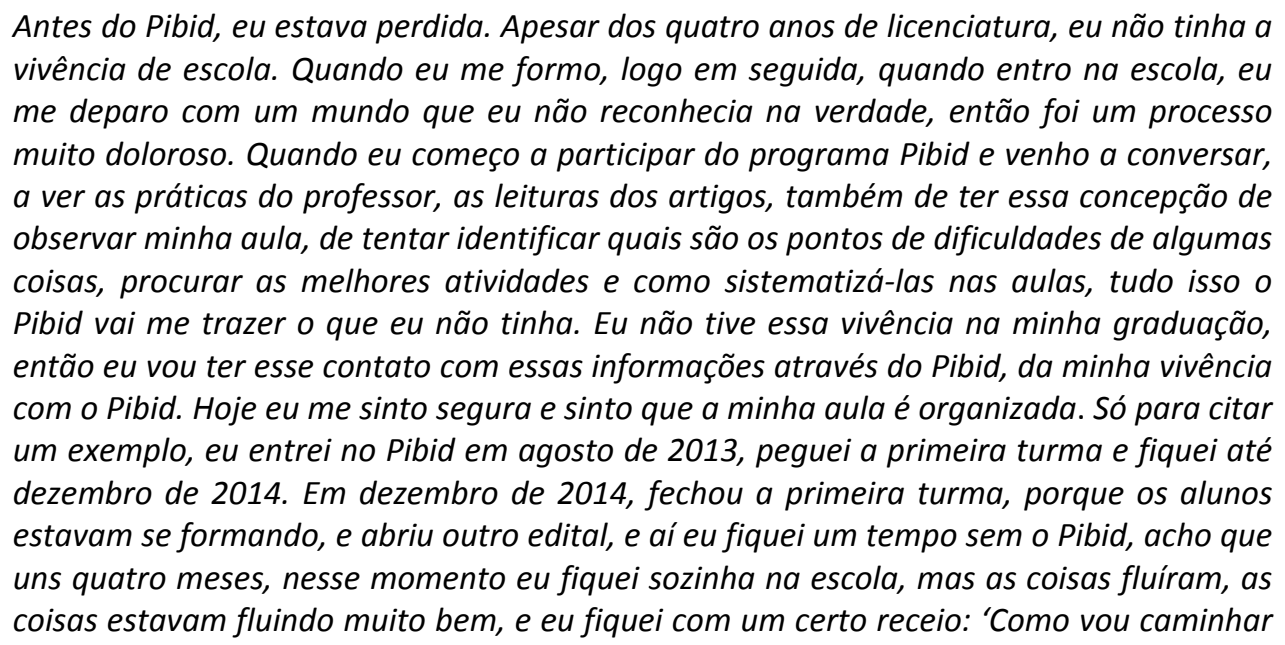


sem o Pibid?', porque minha experiência antes do Pibid não era interessante. Eu vivi uma experiência muito legal com o Pibid, e consegui organizar as atividades, e consegui desenvolver os projetos. (PS1).

Eu me sinto um novo professor, tanto na incorporação de novos saberes quanto na vivência de supervisor. Então, eu me sinto bem mais preparado como professor, isso tem somado bastante à minha formação. [...] Depois da inserção no Pibid, melhorei minha prática pedagógica com certeza, porque, com esse intercâmbio de conhecimento, eu trouxe mais modalidade para os alunos, para os alunos de Caucaia. Se aqui é triste a questão de material, lá é mais triste ainda; então se aqui tem essas carências de práticas... Esse meu conhecimento extrapolou essa escola e alcançou outras escolas onde eu tenho essa minha prática pedagógica como professor. (PS2).

Antes do Pibid, existiam alguns vícios de professores anteriores que não deixavam você crescer; a Educação Física era vista com maus olhos. [...] É tanto que, por exemplo, quando eu trabalhava na polícia (e Pibid), tinha uns alunos que às vezes eu levava para as aulas de primeiros socorros. Tinha até aula de rapel. Então foi uma experiência maravilhosa, posso dizer que o Pibid é só saudades! Embora tenha uma bolsa boa, mas o que eu sempre gostei foi desse contato, eu gosto de ensinar. Foi uma experiência maravilhosa. (PS3).

Eu basicamente adequei os bolsistas no contexto da aula, mas a minha prática eu não mudei tanto, não, eu apenas me adequei à presença dos bolsistas, não mudei muito minha forma de atuar, não, de agir; não mudou! (PS4).

Podemos observar nas falas de PS1, PS2 e PS3 um teor de organização e sistematização das práticas pedagógicas advindas das mudanças por meio do Pibid. Em tais relatos, também identificamos mudanças como: mais segurança nas práticas pedagógicas, sentimento de renovação e confiança como professor, incorporação de novos saberes das práticas e novos olhares para com a Educação Física. Os saberes docentes oriundos da experiência profissional no âmbito do Pibid são identificados pelos PS como ponto central no processo de formação continuada.

Prosseguindo, compreendemos na fala de PS4 que o Pibid não proporcionou mudanças significativas em suas práticas pedagógicas. A experiência, conforme coloca Larrosa (2015), é como sendo a possibilidade de que algo nos aconteça ou nos toque. Há uma mudança no sujeito e, a partir dessa, uma transformação na cultura escolar. Se a experiência não é o que acontece, mas o que nos acontece, duas pessoas, ainda que enfrentem o mesmo acontecimento, não fazem a mesma experiência (LARROSA, 2015).

A mudança faz parte de sua condição como ser finito, incompleto. Mudar supõe novas situações, outros aprendizados, a perda provisória das rotinas e referências (FARIAS, 2006). Essa é uma das propostas do Pibid, inovação e mudança, foi o que pudemos observar nas falas de PS1, PS2 e PS3. 
As mudanças alcançadas pelos PS estão em consonância com as ideias de Ferreira (2012, p. 14), que compreende que "[...] os currículos de Educação Física deveriam realizar profundas mudanças em seus conteúdos, deixando de lado preocupações exclusivamente voltadas ao desenvolvimento de habilidades esportivas e motoras".

\section{CONSIDERAÇÕES FINAIS}

No que concerne ao subprojeto Pibid/Educação Física/UECE, observamos nas falas dos professores que ele proporcionou aprendizagem dos saberes docentes, de forma majoritária. São saberes que reaproximam os docentes das leituras de livros e do ensino por meio da pesquisa.

Dos quatro professores investigados, três afirmaram com veemência que houve mudanças significativas em suas práticas pedagógicas, os quais revelaram que o Pibid foi um divisor de águas. Somente um professor destoou desse posicionamento em seu depoimento, ao afirmar que o Pibid não promoveu muitas mudanças em suas práxis.

Concluímos que o subprojeto Pibid/Educação Física/UECE confirma nossos pressupostos e viabiliza a aquisição de saberes da docência, mas não da mesma maneira e com a mesma profundidade para todos.

\section{REFERÊNCIAS}

BETTI, M. Educação Física e cultura corporal de movimento: uma perspectiva fenomenológica e semiótica. Revista da Educação Física, Maringá, v. 18, p. 207-217, 2007.

BOGDAN, R. C.; BIKLEN, S. K. Investigação qualitativa em educação. Porto: Porto, 1994.

BRACHT, V. Educação Física e aprendizagem social. Porto Alegre: Magister, 1992.

BRASIL. Ministério da Educação. Conselho Nacional de Educação. Parecer CNE/CP no 9, de 8 de maio de 2001. Diretrizes Curriculares Nacionais para a Formação de Professores da Educação Básica, em nível superior, curso de licenciatura, de graduação plena. Diário Oficial da União, Brasília, DF, 18 jan. 2002.

BRASIL. Parâmetros Curriculares Nacionais: Educação Física. Brasília, DF: MEC, 1996.

DAOLIO, J. Fenômeno social esporte na formação profissional em Educação Física. Revista da Educação Física, Maringá, v. 9 n. 1, p. 11-115, 1998. 
FARIAS, I. M. S. Inovação, mudança e cultura docente. Brasília, DF: Liber, 2006.

FERREIRA, H. S. Educação Física e saúde em escolas públicas municipais de Fortaleza: uma proposta de ensino. Fortaleza: UECE, 2012.

GARCIA, C. M. Formação de professores: para uma mudança educativa. 2. ed. Portugal: Porto, 1999.

GAUTHIER, C. et. al. Por uma teoria da pedagogia: pesquisas contemporâneas sobre os saberes docentes. Ijuí: Unijuí, 1998.

LARROSA, J. Tremores: escritos sobre experiência. Belo Horizonte: Autêntica, 2015.

LAZZAROTTI FILHO, A.; SILVA, A. M.; PIRES, G. L. Saberes e práticas corporais na formação de professores de Educação Física na modalidade a distância. Revista Brasileira de Ciências do Esporte, Florianópolis, v. 35, n. 3, p. 701-715, 2013.

NASCIMENTO, J. V. Metodologias de ensino dos esportes: avanços teóricos e implicações práticas. Revista Portuguesa de Ciências do Desporte, Buenos Aires, v. 11, n. 1, p. 115, 2007.

RABELO, F. S.; SILVA, S. P. A formação docente articulada à extensão universitária: os desafios contemporâneos da sala de aula com crianças hospitalizadas. In: FARIAS, I. M. S.; NÓBREGA-THERRIEN, S. M.; CARVALHO, A. D. F. (Org.). Diálogos sobre a formação de professores. Teresina: UFPI, 2013. p. 179-190.

TARDIF, M. Saberes docentes e formação profissional. 17. ed. Petrópolis: Vozes, 2014.

UNIVERSIDADE ESTADUAL DO CEARÁ - UECE. Programa de Bolsa de Iniciação à Docência. Ampliação da perspectiva de formação em Educação Física: aprendendo a ensinar. Detalhamento do subprojeto de Educação Física. Fortaleza: UECE, 2012.

UNIVERSIDADE ESTADUAL DO CEARÁ - UECE. Programa de Bolsa de Iniciação à Docência. Educação Física na Escola e Saúde: uma proposta para formação de futuros professores. Detalhamento do subprojeto de Educação Física. Fortaleza: UECE, 2013.

Recebido em 28 de junho de 2016.

Aceito em 31 de julho de 2016. 